\title{
Production Efficiency in Small Agriculture: Do Migrant Remittances Matter? Evidence from Rural Nigeria
}

\author{
John C. Odozi*, Oluwatosin Adeniyi ${ }^{\dagger}$ and Sulaiman A. Yusuf $\ddagger$
}

October, 2018

Paper accepted for presentation at the 19th Annual Conference of Nigerian Association of Agricultural Economists (NAAE) NAAE KADA 2018 . Theme: Diversification of the Nigerian Economy: where lies Agriculture: 15th - 18th Octobe, 2018

\begin{abstract}
This paper investigates how remittances flow to Nigeria from household migrants correlate with farm production efficiency of the left behind in rural areas using the Living Standard Measurement Survey data set. We applied the production frontier model from which efficiency scores for two groups of farmers were recovered: migrant households and non-migrant households. We subjected the efficiency scores to Anova and stochastic dominance analyses. Mean production efficiency for migrant households was signifcantly higher at $p<0.05$. Across all percentiles, migrant households had higher technical efficiency level compared to households with out migrants. Thus rejecting the hypothesis of negative production efficiency effect of migrant remittances flow to farm households. While policy programmes should promote labour mobility and remittances, it supposes a complementary policy that promote labour saving farm technologies.
\end{abstract}

JEL classification: D13, D61, J22, J61, Q12

Keywords: Migrant Remittances; Production Efficiency; Rural Agriculture

${ }^{*}$ chiwuzulum@yahoo.com, Department of Economics, Edo University Iyamho, Edo State, Nigeria

${ }^{\dagger}$ Department of Economics, University of Ibadan

${ }_{\ddagger}^{\ddagger}$ Department of Agricultural Economics, University of Ibadan 


\section{Introduction}

Despite the importance of agriculture in Nigeria's economic development, a number of factors constitute a drag to agricultural productivity. Factors documented in literature include climate change, inappropriate economic policies, low adoption of improved agricultural technologies, violent conflict and production inefficiency. Raising agricultural productivity requires that farmers take decisions regarding technology development, innovations and efficient use of technology. At the core of agriculture is the notion of efficiency defined as the ability of farms to utilize the best available technology and to allocate resources productively" (Chavas et al., 2005). Variation in socioeconomic characteristics tends to cause differences in production efficiency amongst farmers, which then lead to variations in total output. Although, farmer-specific variables such as age, education, access to extension, credit (Parikh and Shah, 1994; Llewelyn and Williams, 1996 Amaza and Olayemi (2002); Amaza et al.,(2006)) have been linked to farm production efficiency. There is limited empirical information on the role of migrant remittances on the technical know how of migrant households. Remittance is that portion of migrants' income sent home either in cash or in kind; within and across borders (Quartey 2006, Chukwuone 2007). Together with other non-farm income, the share ranges from 30 to 40 per cent to more recent findings of 60 to 80 per cent (Ellis, 1998, Bryceson (1999), Bah et al., 2010)). Estimates by Central Bank of Nigeria puts workers remittances and other transfers in kind at N2715.1 billion in 2009 and increased to N2943.4 billion in 2010 and 3145.8 billion in 2011. The number of recipients, according to the Bureau of National Statistics, is estimated at eight million, eight hundred and seventy two thousand, six hundred and fifty nine $(8,872,659)$ persons. When disaggregated by location, rural recipients are believed to be more $(6,056,240$ persons) compared to urban recipients (2,816,419 persons) and male recipients $(4,758,244$ persons) than female (4,101,028 persons).

Although there is no common point of view on the relationship between remittances and economic growth, remittances can affect positively the economy in the following ways: improvement of financial intermediation managing remittances e.g. by banks; extension of investment credit allowed by the increase in the liquidity of banks from remittance deposits; investment in human capital in the form of spending on certain consumption items e.g. education, health; purchase of more investment goods. In addition, smoothing income inequality in the short term; diversification; growth of investment as a result of the multiplier effects of spending on consumption.(Glytsos, Nicholas P A(2002) Stratana and Chistrugaa(2012)). In Nigeria, the availability of liquidity in the form of remittances can help households to better 
respond to farm management imperatives in terms of the level and timing in the use of labour, herbicide, pesticide, fertilizer and seed. Nonetheless, the disincentive problem of migration on the production efficiency of sending households has been noted in literature. Wouterse, (2010) finds that while intercontinental migration provides households with the required liquidity, technical efficiency did not improve in Burkina Faso. Hyden et al. (1993) conclude that many African households experience diminished agricultural production and display inadequate land improvements, primarily due to the absence of male labour, but also point to large regional variations in impacts. However, in countries like Nigeria characterised by credit limiting and labour intensive agriculture, there is need to investigate whether the negative migrant remittances effect on production effciency holds for Nigeria. If remittances figure into the calculation of net benefits of farm households, then, allocating time to migration work becomes beneficial. In other words, the policy objective of rural authorites become how to complement or substitute labour mobility out of agriculture with cost effective labour saving farm implements. While current studies in Nigeria have addressed the economic consequences of migrant remittances in relation to poverty and inequality, there is limited empirical knowledge on the role of migrant remittances on the technical efficiency of crop farmers.

This study compares the technical efficiency between migrant and nonmigrant farm households. The overall structure of this paper is organised in the following manner. Following the introduction is section two which gives a review on relevant literature, section three discusses the methodology that includes the theoretical framework, model specification and data. Section four discusses the results while section five concludes.

\section{Materials and Method}

\subsection{Conceptual/Analytical Framework}

The economic consequences of migration and remittances can be approached from three broad perspectives: the migrant, the sending households and the inhabitants in the destination countries (Lucas, 2006). This study is approached from the perspective of sending households. That is what happens to agricultural production efficiency in sending rural households. We follow the proposition that technical effciency differential across farms relates with differences in farmer's decisions on the level and timing in the use of labour, capital, herbicide, pesticide, fertilizer and seed. Production efficiency 
is directly related to the technical know-how and the socio-economic characteristics of farmers. Hence the notion of farm efficiency can be seen as tied to farm management decisions. Differences in output across farms can therefore be attributable to management decisions in terms of level and timing in the application of inputs such as labour, capital, herbicide, pesticide, fertilizer and seed. The relationship between migration activity and agricultural production can be modelled within the farm household theoretical framework. This framework underlies the many studies that have looked at off-farm activities and agricultural productivity and production risk. Production efficiency is often investigated as technical efficiency (TE) or cost efficiency (AE) or in a holistic manner as economic efficiency (EE). Kumbhakar (2002), Chang and Wen (2011) and Picazo-Tadeo and Wall (2011) presents a production function model in which households are endowed with aggregate time endowment $\bar{E}$ allocated among farm production (L), leisure (L) and migration work $\left(L_{m}\right)$. Total income generated is used to purchase farm inputs for the production function specified as $\mathrm{F}(\mathrm{L})=\mathrm{f}(\mathrm{L})$. Given a well behave household utility function that depends on consumption (C) and leisure (L), household utility is maximized subject to the time endowment and cash income constraints.

$$
\max _{L, L_{m}}=E U\left(\left(P *(f(L))+w * L_{m}\right),\left(\bar{E}-L-L_{m}\right)\right)
$$

Where $\mathrm{EU}($.$) is the expected utility of each farm, and \mathrm{P}$ and $\mathrm{w}$ represent respectively price of output produced and equilibrium migration work wage rate. Solving the model yields the first-order necessary Kuhn-Tucker conditions for the optimal allocation of time to farm production and migration work. This is expressed in the equations below.

$$
\begin{gathered}
\frac{\partial E U(.)}{\partial L}=\frac{\partial E U(.) * P *(f L)}{\partial C}-\frac{\partial E U(.)=0}{\partial L} \\
\frac{\partial E U(.)}{\partial L_{m}}=\frac{\partial E U(.) * w}{\partial C}-\frac{\partial E U(.) \leq 0 ; \geq 0}{\partial L} \\
\frac{\partial E U(.) * L_{m}=0}{\partial L_{m}}
\end{gathered}
$$

Solving equations two and three above simultaneously yields two possible optimal labour allocations: $L_{1}^{*} L_{m}^{*}$ for households that participate in migration work and $L_{0}^{*}, 0$ for households that do not engage in migration work. Estimation requires randomised data or panel data set to measure differences in output between migrant and non-migrant households. The use of cross sectional data presents the problem of simultaneity. Migrant earnings are 
generally not randomly allocated across households. Observed relationship between remittances and farm production outcomes may simply reflect the influence of unobserved third factors. For example, households with greater unobserved entrepreneurial ability could have more migrants, receive larger remittances and also have higher investment levels (Yang, 2011). Correcting for simultaneity is possible econometrically using instrumental variables. This is, however, limited by the difficulty of finding appropriate instruments in cross sectional data. Using invalid instruments can lead to worse estimates when compared to the case where there is no correction for self-selection bias (Wooldridge, 2002).Although Heckman's method can be used to correct for simultaneity, Chang and Wen (2011) points out that deriving the symbolic forms of the correction terms is not obvious in a stochastic production frame work, because of the composited error term. Secondly, the use of Heckman to control for sample selection bias is inappropriate for models that are not linear, such as Probit and Tobit. To circumvent these intricacies we estimate two separate production models for migrant and non-migrant households using the frontier estimation approach. The production frontier reflects the maximum output obtainable from a set of available resources and inputs.

\subsection{Data and Variables}

The study used the data set from the National Bureau of Statistics of the federal government of Nigeria. Relevant to this study is the module: General Household Survey with panel component (GHS-Panel) for 2010. It forms part of a regional project, Living Standards Measurement Study-integrated Surveys on Agriculture LSMS-ISA in Sub-Saharan Africa by World Bank. The survey covered three sets of data corresponding to household, agriculture and community questions. To answer our objective, the agricultural module was used. It was designed to gather responses on farm household production system such as technology and inputs used and output obtained. Of the 5,000 households covered 3000 are agricultural but 2683 were found useful after merging with relevant household files. Analysis was done at the farm household level. Key to this analysis is the question on whether farm households received remittances. This variable was used to disaggregate total households into migrant and non-migrant. 527(20\%) are migrant households while $2143(80 \%)$ are non-migrant households. Another key variable is output per plot. From the data set, $69 \%$ of the respondents measured yield per plot in $\mathrm{kg}, 3 \%$ measured in bunches, $11 \%$ in pieces and $15 \%$ unclassified. Since households using unconventional measures are few, we dropped some households to allow the measure of output in $\mathrm{Kg}$ per plot. One important input variable is plot area allocated for crop cultivation. In the data set 
farmers were asked to quantify the total area planted on their plots with crops. Use of this variable is made difficult by the different measures of plot area planted. About $80 \%$ of farmers used unconventional measures such as heaps, ridges and stands while less than $25 \%$ use conventional measures such as plots, acres, hectares and square meters. Converting unconventional to conventional measures is problematic because of differences in landscape and pattern of ridge making in Nigeria. For this reason we used plot size as measured by GPS in meters square and finally converted to acres. All other variables are listed and defined in table 1 of the appendix. Production inputs include measures of land, fertilizer and seeds, extension services, and labour supply measured in hours spent on crop production. In addition, we included tenure security variables which reflect farmers' ability to secure or make improvements upon land as well as crop indicators aggregated at the household level. Community-level indicators include agro ecological zones and rural dummy. The various variables and their definitions are presented in appendix table.

\subsection{Model Specification and estimation}

$$
\begin{aligned}
& \operatorname{lny}_{i}=\alpha_{0}+\alpha_{1} \ln \left(\text { farmsize }_{i}\right)+\alpha_{2} \ln \left(\text { labour }_{i}\right)+\alpha_{3} \ln \left(\text { capital }_{i}\right) \\
& +\alpha_{4} \ln \left(\text { herbicide }_{i}\right)+\alpha_{5} \ln \left(\text { pesticide }_{i}\right)+\alpha_{6} \ln \left(\text { fertilizer }_{i}\right) \\
& +\alpha_{7} \ln \left(\text { seed }_{i}\right)+v-u
\end{aligned}
$$

$l n y_{i}$ represents the logarithm of the quantity of food crop produced and the vector of parameters that characterize the production frontier. The error term is composite and consists of $v_{i}$ error term representing those factors that cannot be controlled by farmers as well as measurement error in the dependent variable, and omitted explanatory variables. The component $u_{i}$ is a nonnegative error term representing the shortfall of output from the production frontier due to technical inefficiency. To account for the presence of technical inefficiency, it is assumed that the random component $v_{i}$ is distributed as $N\left(0, \sigma_{v}{ }^{2}\right)$ while the production inefficiency effect $u_{i}$ is distributed as $N\left(0, \sigma_{u}^{2}\right)$. Both components are also assumed to be independent and identically distributed across observations. The composite error term $(v-u)$ is assumed to be asymmetric. When $u_{i}=0$, the composite error term is said to be symmetric and defines the absence of technical inefficiency. In which case stochastic regression approach becomes inapplicable. To derive the deterministic parameters of the frontier function and the production efficiency of each farmer we used maximum likelihood estimation utilizing the frontier statistics in STATA 11 package. Analysis was carried out at the sample mean. To determine whether the output- input data support stochastic frontier, we 
used the OLS estimates of equation 5 above to estimate a residual upon which the presence of technical inefficiency was assessed. A negative sign of the third moment and the skewness of the OLS residuals imply presence of inefficiency (Rahman, 2011). We observed negatively skewed OLS residuals in which case we estimated equation 5 using frontier regression. We used the Cobb-Douglas functional form based on its property of quasi-concavity and monotonicity. It is also the most common specification used for estimating agricultural production function (Lio and Liu, 2006). The likelihood function was used to generate the variance parameters. $\lambda$, indicates a good fit and correctness of the specified distributional assumption. If it exceeds one in value, the one sided error term $\mathrm{u}$ is said to dominate the symmetry error $\mathrm{v}$. We derived $\gamma$ from $\lambda$ using the formular

$$
\gamma=\frac{\lambda^{2}}{1+\lambda^{2}}
$$

$\gamma$ has a value between zero and one and defines the total variation of output from the frontier. The closer the estimated value of $\gamma$ is to one, the higher is the probability that technical inefficiency is significant in explaining output variability among sample participants. Also generated from the maximum likelihood estimation is a vector of coefficients of the inputs included in equation 5 .

\subsection{Production efficiency index}

From the error term we disentangle the production efficiency $u_{i}$ for each farmer calculated as $T E_{i}=E\left(\exp \left(-u_{i}\right) \mid \hat{\epsilon}_{i}\right)$. We used this parameter to rank the aggregate efficiency of migrant farm households and non-migrant households using the Lorenz dominance and inferential statistics as applied in Bishop et al (1992). Lorenz dominance is said to exist if the Lorenz curve for one distribution dominates that for another. The two distributions are the technical efficiencies for migrant and non-migrant households denoted as

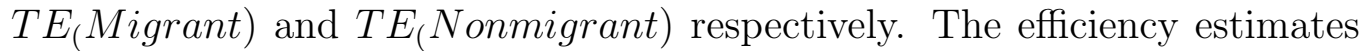
$T E_{i}$ range between 0 and 1 , with 0 indicating the least efficient and $1\left(u_{i}=0\right)$ the most efficient. Both distributions were assumed to be independent with finite mean and variance. Households were assumed identical except in terms of their technical efficiencies. From the distribution of technical efficiencies

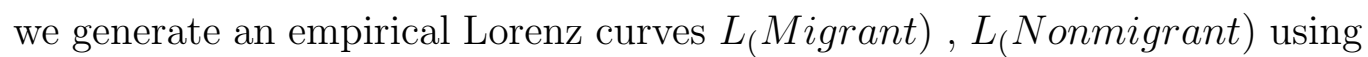
the DASP programme in STATA 11 package. 


\section{Results and Discussion}

\subsection{Summary statistics}

Table 1 shows the summary statistics of the selected variables for migrant and non-migrant households. Mean production yield was significantly higher for households with migrants $(32389.81 \mathrm{~kg} /$ acre $)$ than for households without migrants $(8854.08 \mathrm{~kg} /$ acre). The t-test presented in the last column of the table suggests statistical significance. Farm revenue was also statistically higher for migrant households than non-migrant households. The average age of migrant household head was significantly higher than non-migrant. Also the proportion of migrant household heads with no formal education was significantly lower than for non-migrant household head. The proportion of migrant household head with secondary and tertiary education was significantly higher than for non-migrant household head. However, household size was significantly larger for non-migrant households. Among the input used, own animal traction per day, herbicides and pesticides in liters per acre were significantly higher for migrant households. However, the number of days of labour in hours, fertilizer input and seeds were significantly lower for the migrant households. Migrant households had smaller land size; used less of labour hours and fertilize 
Table 1: Summary Statistics

\begin{tabular}{|l|c|c|c|c|c|}
\hline & \multicolumn{2}{|c|}{ Migrant } & & Nmigrant & \\
\hline W-griables & Mean & SD & Mean & SD & T-ratio \\
\hline Age & 57.01 & 16.33 & 48.99 & 14.14 & $10.32^{*}$ \\
age2 & 3516.59 & 1846.08 & 2600.59 & 1482.8 & $11.02^{*}$ \\
No formal education & 0.13 & 0.33 & 0.2 & 0.4 & $3.26^{*}$ \\
No education & 0.06 & 0.24 & 0.06 & 0.24 & -0.34 \\
Primary education & 0.63 & 0.48 & 0.62 & 0.48 & -0.43 \\
Secondary education & 0.15 & 0.36 & 0.11 & 0.32 & $-2.13^{*}$ \\
Tertiary education & 0.02 & 0.16 & 0.01 & 0.09 & $-2.70^{*}$ \\
Household size & 5.44 & 3.44 & 6.45 & 3.28 & $-5.75^{*}$ \\
Female headed & 0.35 & 0.39 & 0.18 & 0.28 & $-6.42^{*}$ \\
Yield & 32389.8 & 332609 & 8854.08 & 90593 & $-2.56^{*}$ \\
Farm size in acres & 1.95 & 4.54 & 3.16 & 10.39 & $2.38^{*}$ \\
Fertilizer kg/year & 91.34 & 131.24 & 124.69 & 147.75 & $2.84^{*}$ \\
Pesticide in litres/year & 25.59 & 73.13 & 21.59 & 86.22 & -0.34 \\
Herbicide in liters & 40.88 & 273.66 & 10.23 & 43.19 & $-2.32^{*}$ \\
Seeds in kg & 37.16 & 88.17 & 38.02 & 92.83 & 0.12 \\
Own animal traction used(days) & 2.91 & 4.48 & 2.68 & 3.59 & -0.51 \\
Hired animal traction(days) & 1.3 & 1.51 & 1.24 & 2.25 & -0.26 \\
Labour in hrs & 95.67 & 73.72 & 114.48 & 87.57 & $4.16^{*}$ \\
Land worth(N) & 984798 & 3065057 & 925702 & $5 \mathrm{E}+06$ & -0.261 \\
Land price(N) & 5875.81 & 36863.6 & 13675.2 & 149875 & 1.08 \\
Farm revenue(N) & 22863.7 & 78576.6 & 18436.1 & 67239 & -1.2 \\
Remittances received (N) & 24754.9 & 52718 & 0 & 0 & -19.91 \\
\hline
\end{tabular}




\subsection{Migrant and Non-Migrant Deterministic Frontier Results}

Table 2 presents the results of the stochastic production frontier model. The estimated parameters along with their corresponding standard errors and $t$ values are reported for migrant and non-migrant households. Also reported are the variance parameters, derivatives from the variance parameters and log-likelihood ratio test. The test statistics of the likelihood ratio test are 190 and 1000 for migrant and non-migrant households respectively. This suggests appropriateness of the empirical specification of the efficiency function. Therefore, the hypothesis that the effect of the exogenous determinants of production efficiency is statistically equal to zero $(H 0:=0)$ was rejected. The high $\gamma$ value of 0.95 also supports the structural appropriateness of the model specification since it defines the total variation of output from the frontier. That is the included inputs together explain the variation of the observed output from the frontier. The sigma squared $\sigma^{2}$ is 1.296 and 1.832 respectively. The values are statistically significant and indicate the goodness of fit and correctness of the distributional form assumed for the composite error term. This study assumes the exponential functional form. $\lambda$ is 4.3566 which exceed one in value suggesting that the one sided error term $u$ dominates the symmetry error v. This indicates a good fit and correctness of the specified distributional assumption. The variables shown in the table are all significantly different from zero at the $5 \%$ level. The coefficients are all positive and range between one and zero. However, differential input-output elasticity is observed between the two groups of farmers. The results indicate that while the output response for migrant households is higher than non-migrant households in terms of farm size (0.084vs 0.002), capital (0.039 vs. 0.014) and seed (0.893vs 0.342), in terms of labour, herbicide, pesticide and fertilizer, the output response is lower for migrant households. 
Table 2: Deterministic frontier results for Migrant and Nonmigrant Households

\begin{tabular}{|c|c|c|c|}
\hline \multicolumn{4}{|c|}{ MIGRANT } \\
\hline Variables & Coefficient & SE & T- test \\
\hline Ln_farrm_size & 0.08 & 0.02 & 3.6 \\
\hline Ln_labour 2 & 0.73 & 0.12 & 6,13 \\
\hline Ln_capital & 0.04 & 0.01 & 7.74 \\
\hline Ln_pesticides 4 & 0.41 & 0.08 & 5.2 \\
\hline Ln_herbicides 5 & 0.65 & 0.33 & 1.97 \\
\hline Ln_Fertilizer 6 & 0.34 & 0.17 & 2.06 \\
\hline Ln_seeds 7 & 0.89 & 0.24 & 3.66 \\
\hline Constant 0 & 9.99 & 0.58 & 17.18 \\
\hline lambda & 4.36 & 0.1 & 43.57 \\
\hline Sigma squared & 1.3 & 0.15 & 8.34 \\
\hline Gamma & 0.95 & & \\
\hline Log likelihood & -494.51 & & \\
\hline Log likelihood test & & & 190 \\
\hline Wald $\left(\chi^{2} 9,95\right)$ & & & 222 \\
\hline \multicolumn{4}{|c|}{ NON-MIGRANT } \\
\hline Ln_farrm_size 1 & 0.002 & 0.005 & 3.9 \\
\hline Ln_labour 2 & 1.97 & 0.07 & 27.25 \\
\hline Ln_capital 3 & 0.01 & 0.004 & 3.12 \\
\hline Ln_pesticides 4 & 0.65 & 0.05 & 13.53 \\
\hline Ln_herbicides 5 & 0.68 & 0.09 & 7.19 \\
\hline Ln_Fertilizer 6 & 0.64 & 0.07 & 8.47 \\
\hline Ln_seeds 7 & 0.34 & 0.05 & 6.99 \\
\hline Constant 0 & 12.3 & 0.3 & 41.01 \\
\hline lambda & 21.05 & 0.04 & 5612 \\
\hline Sigma squared & 1.83 & 0.09 & 19.402 \\
\hline Gamma & 1 & & \\
\hline Log likelihood & -2187.24 & & \\
\hline Log likelihood test & & & 1000 \\
\hline Wald $\left(\chi^{2} 9,95\right)$ & & & 2146.9 \\
\hline
\end{tabular}




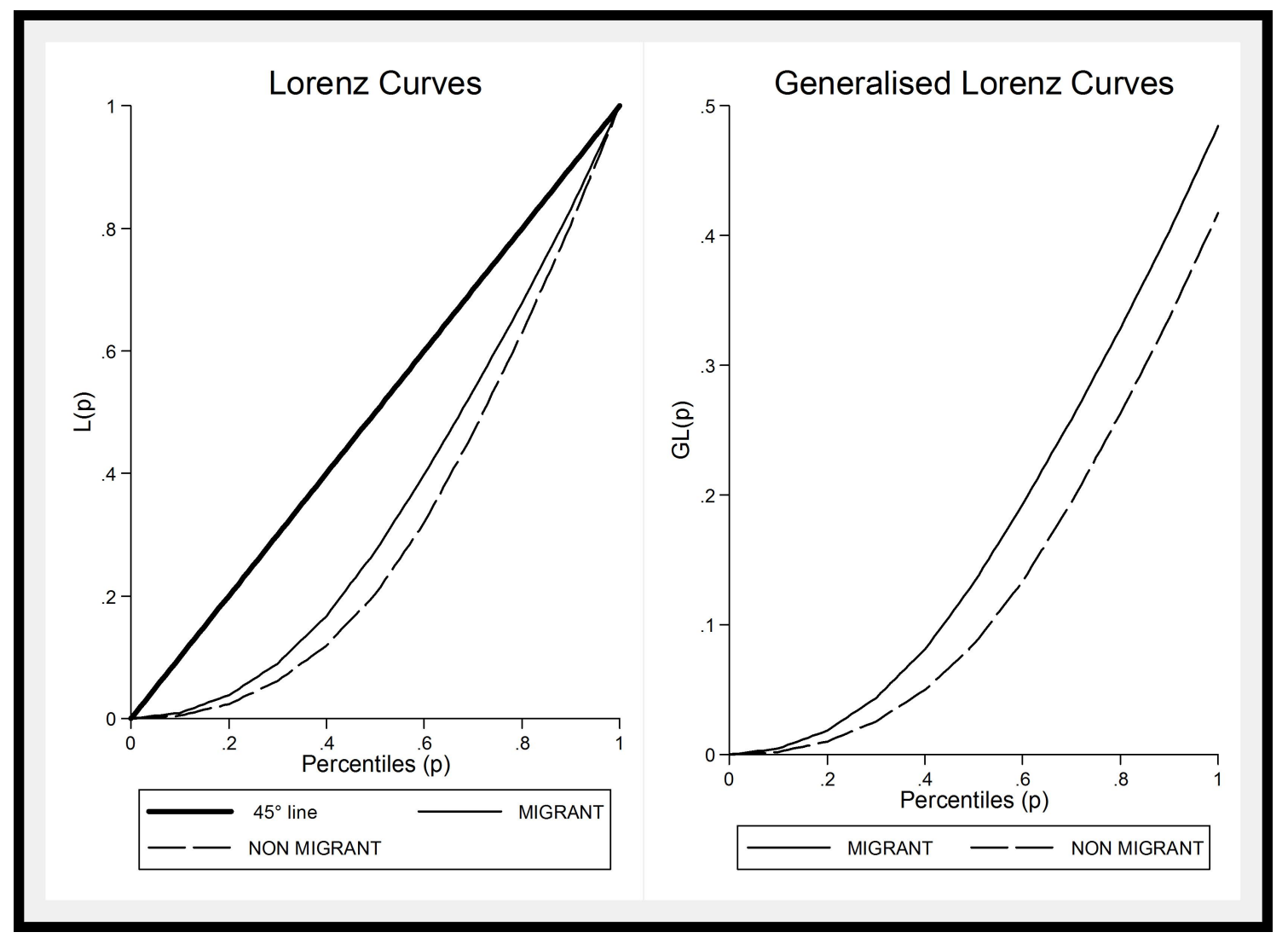

Figure 1: Efficiency Score Dominance Curves for migrants and nonmigrant household farms

\subsection{Aggregate migrant and non-migrant production ef- ficiency index: Test of dominance}

Do the estimated production efficiencies between migrant and non-migrant households presented in table 3 give any clear indication of differences? The easiest way is to examine the values visually and apply the t-statistics. As shown in the table, the mean production efficiency for migrant and nonmigrant households amounted to 0.48 and 0.42 respectively. Across all percentiles, technical efficiencies for migrant households were higher. The t-test suggests statistical significance at $\mathrm{p}_{\mathbf{0}} 0.05$. Thus the null hypothesis that there is no significant difference in production efficiency between the two categories of households was rejected. Observed differences can be attributed to differences in the amount of timely consumption of inputs and available income 
Table 3: Percentile distribution of migrant and non-migrant production efficiency index

\begin{tabular}{|c|c|c|c|c|c|c|}
\hline \multicolumn{3}{|c|}{ MIGRANTS } & \multicolumn{2}{|c|}{ NONMIGRANTS } & \multirow{3}{*}{$\begin{array}{l}\text { DIFF } \\
0.066\end{array}$} & \multirow{3}{*}{$\begin{array}{r}\text { t-test } \\
4.28\end{array}$} \\
\hline Mean & & 0.483 & & 0.417 & & \\
\hline SD & & 0.256 & & 0.274 & & \\
\hline Deciles & Mean & SD & Mean & SD & Diff & t-test \\
\hline 1 & 0.045 & 0.029 & 0.02 & 0.016 & 0.025 & 0.118 \\
\hline 2 & 0.14 & 0.041 & 0.08 & 0.019 & 0.059 & 0.244 \\
\hline 3 & 0.252 & 0.033 & 0.156 & 0.025 & 0.096 & 0.398 \\
\hline 4 & 0.372 & 0.041 & 0.242 & 0.025 & 0.129 & 0.504 \\
\hline 5 & 0.515 & 0.041 & 0.35 & 0.04 & 0.165 & 0.579 \\
\hline 6 & 0.603 & 0.017 & 0.487 & 0.042 & 0.116 & 0.478 \\
\hline 7 & 0.659 & 0.016 & 0.611 & 0.025 & 0.048 & 0.235 \\
\hline 8 & 0.701 & 0.009 & 0.683 & 0.017 & 0.018 & 0.11 \\
\hline 9 & 0.741 & 0.015 & 0.736 & 0.015 & 0.005 & 0.03 \\
\hline 10 & 0.817 & 0.042 & 0.811 & 0.038 & 0.007 & 0.024 \\
\hline
\end{tabular}

between the two category of households. However, to what extent can allocation of labour to migration activities be relied for higher production efficiency?

To understand this issue, we carried out a robustness check using the Lorenz and the generalized dominance test. Figure 1 presents the Lorenz and generalized Lorenz curves for migrant and non-migrant. The Lorenz chart reflects dominance of migrant household production efficiency over nonmigrant household. The same pattern is observed for the generalized curve chat. However, observed crosses of Lorenz curves at the extremes of the distribution suggest ambiguous conclusion on the effect of remittances on crop production. Therefore it can be said that the flow of domestic remittances to migrant households for increased consumption and investment might not be enough to countervail the loss of labour for agricultural production in some segments of the population. Since migration entails loss of labour, in an economy where markets for labour is missing, migrant households might fall short of labour stock during planting and harvesting seasons particularly for domestic migration. 


\section{Conclusion}

This study used a nation-wide household survey data collected in 2010 to estimate a deterministic production frontier from which production efficiency index was estimated and used to examine the production efficiency of migrant and non-migrant farm households. We used the Lorenz dominance approach to rank distributions of the estimated technical efficiency for the two groups. Empirical results showed that across all percentiles, migrant households had a higher aggregate technical efficiency values relative to nonmigrant households. The T-statistics revealed that mean technical efficiency index for migrant households was significantly higher than for non-migrant households at $5 \%$ significant level. However the much we know about the role of remittances in development means that polices that will enhance labour mobility and remittances flow will go a long way to enhance production efficiency. But this has to be complemented with agricultural policies that promote cost effective labour saving farm implements. Since economic development and growth are known to associate with agrarian transformation. Therefore there is the need to advance and promote labour saving technologies in agriculture. Further studies in this area are recommended through the use of panel data, experimental data and case studies to map out the role of migrant remittances in agriculture.

\section{References}

[1] Amaza, P. S. and Olayemi, J. K.(2002) ; An analysis of technical inefficiency in food crop production in Gombe State, Nigeria; Applied Economics Letters; 9:51-54; 2002.

[2] Amaza, P. S. Bila, Y and Iheanacho, A.C.(2006) Identification of Factors that Influence Technical Efficiency of Food Crop Production in West Africa: Empirical Evidence from Borno State, Nigeria Journal of Agriculture and Rural Development in the Tropics and Subtropics Volume 107, No. 2, 2006, pages 139-147

[3] Bah M, Salmana C, Bitrina D, Gouro D, Fred L, David O, Enoch O, Janice O, Cecilia T, 2003. Changing Rural-Urban Linkages in Mali, Nigeria and Tanzania. Environment Urbanization 15(1): 3-24.

[4] Bishop A, Formby P, Thistle 1992.Convergence of the south and Nonsouth income Distributions, 1969-1979. The American economic Review 82(1): 262-272. 
[5] Chang H, and Wen F, 2011. Off-farm work, technical efficiency, and rice production risk in Taiwan Agricultural Economics 42(2): 269-278

[6] Chukwuone N, 2007.Analysis of impact of remittance on poverty and inequality in Nigeria. Sixth PEP Research Network General Meeting [[online]]. www.pep-net.org.

[7] Coelli TJ, Rahman S Thirtle C, 2002. Technical, allocative, cost and scale efficiencies in Bangladesh rice cultivation: A nonparametric approach. J. Agric. Econ. 53(3): 607-626.

[8] Dillon, A, Mueller V, Salau S, (2011).Migratory responses to agricultural risk in Northern Nigeria Amer. J. Agr. Econ. 93(4): 1048-1061

[9] Glytsos, Nicholas P A(2002) Macroeconometric Model of the effects of Migrant Remittances in Mediterranean Countries," In human capital: Population Economics in the Middle East, ed. Ismail Abdel-Hamid Sirageldin(Cairo American University in Cairo Press, 2002) cited in Ozden and Schiff, Overview, pp, 7-8. National Bureau of Statistics, www.statistica.md

[10] Gubert F, 2002. Do migrants insure those who stay behind? Evidence from the Kayes Area (Western Mali).Oxf. Dev. Stud. 30(3): 267-287

[11] Hagen-Zanker J Siegel M, 2007 The determinants of remittances: A review of the literature Working Paper MGSoG /2007/WP003 Maastricht University Maastricht Graduate School of Governance

[12] Kalirajan, K.P. and Shand, R.T.(1990) Determinants of Production Efficiency: The Case Of Rice Production In Antique Province, Philippines. International Economic Journal. 4(3)

[13] Kihangire, D. and Katarikawe, M. 2008. The impact of remittances on macroeconomic stability andfinancial sector deepening: opportunities and challenges for Uganda. Bou Working Papers [[online]]. http://www.bou.or.ug/bouwebsite/

[14] Kuiper M, 2005. Village modeling: A Chinese recipe for blending general equilibrium and household model. Unpublished Ph.D. thesis, Wageningen University, Wageningen, The Netherlands.

[15] Kumbhakar S, 2002. Specification and estimation of production risk, risk preference, and technical efficiency. Am. J. Agric. Econ. 84(1): 8-22. 
[16] Meng-Chun L, 2006 . ICT and agricultural productivity: evidence from cross country data Agricultural Economics 34(3): 221-228

[17] Llewelyn, R. V. and Williams, J. R.(1996); Non-parametric analysis of technical, pure technical and scale efficiencies for food crop production in East Java, Indonesia; Agricultural Economics; 15:113-126; 1996.

[18] Parikh, A. and Shah, M.(1994); Measurement of technical efficiency in the northwest frontier province of Pakistan; Journal of Agricultural Economics; 45(1):132-138; 1994.

[19] Picazo-Tadeo AJ and Wall A, 2011. Production risk, risk aversion and the determination of risk attitudes among Spanish rice producers Agricultural Economics 42 (4):451-464

[20] Quartey P, 2006. The impact of migrant remittances on household welfare in Ghana. Research paper 158, African economic research consortium, Kenya Nairobi.

[21] Rahman S. 2011. Resource use efficiency under self-selectivity: the case of Bangladeshi rice producers The Australian Journal of Agricultural and Resource Economics. 55(2):273-290

[22] Stratana, Alexandru and Chistrugaa, Marcel(2012) Economic consequences of remittances. Case of Moldova Procedia Economics and Finance 3:1191 - 1195

[23] Wooldridge J, 2002. Econometric Analysis of Cross Section and Panel Data. The MIT Press, Cambridge, MA.

World Bank, (1992) Staff Appraisal Report. National Fadama Development Project, Kano. Nigeria. The World Bank.

[24] Yang D, 2011.Migrant Remittances. Journal of Economic Perspectives. $25(3): 129-52$ 